\title{
UNA INDAGACIÓN ESTÉTICA DEL DR. JOSE GAOS
}

Resulta excepcional que el doctor Gaos se haya ocupado, como tema específico, de la actividad estética del hombre. Cierto que se explica el asunto ya que está enclavado y forma parte de una serie de reflexiones que componen un curso de Antropología Filosófica, uno de los últimos, o quizá el postrero, que dictó en la Facultad de Filosofía y Letras, de la Universidad Nacional Autónoma de México. En el desarrollo de $4^{8}$ lecciones que ahora forman el libro, inédito, titulado: Del hombre, tres de ellas, las números 39, 40 y $4^{1}$, están dedicadas a "Las artes útiles", "Las bellas artes no de la palabra" y "La expresión literaria"."

Nos atendremos, pues, a estos textos, mas teniendo presente que el curso comprende una variedad de temas, todos relativos a la expresión humana, que constituyen un sistema con el cual quiso el autor dar razón del hombre por la filosofía; así, las lecciones referentes al aspecto estético vienen a ser un subsistema, el de la expresión artística, con su introducción, análisis fenomenológicos y conclusiones. Por tratarse de lecciones, los temas tienen cierta limitación en el desarrollo expositivo, y aun, a veces, alguna desproporción en los puntos considerados, pero siempre dando lo debido a lo que es capital en cada tema.

Es necesario tomar nota, por lo que más adelante se encontrará en relación con el hombre estético y el arte bello en general, de que el doctor Gaos se atuvo, como punto de partida de su indagación, a la clásica definición del hombre como "animal racional", y a sus expresiones primarias o esenciales: la mímica y la verbal, tras las cuales considera la expresión artística.

La expresión humana, fenómeno comprobable, fue de interés capital en el pensamiento del doctor Gaos, como vía de aproximación a aquellos rasgos esenciales que distinguen al hombre de todo otro ser viviente. Recuerdo que el primer curso que dictó, recién llegado a México, en la Facultad de Filosofía y Letras (en su antigua sede en el edificio llamado "Mascarones"), fue sobre La expresión. Es curioso que el último curso que dictara fuese el que nos ocupa, basado fundamentalmente en la expresión humana; y es que tras la inevitable decepción filosófica, común en nuestros días de crisis, el doctor Gaos se atuvo a algo concreto: la Antropologia Filosófica, "a la que compete

- Agradezco al Dr. Fernando Salmerón que me haya invitado a colaborar en Didnoia y que me facilitara copia de las lecciones mencionadas, para considerarlas especialmente en este homenaje a la memoria del maestro Dr. José Gaos, a cuyos cursos asistf́ por largos años en la Facultad de Filosofía y Letras. 
únicamente -según dice-: señalar y acotar el lugar y la raíz de las cuestiones (las artísticas en este caso) en la esencia del hombre".

En una breve introducción a "Las artes útiles" enuncia ya algunas generalidades; que el hombre se expresa no sólo mímica y verbalmente (temas que trata con amplitud en las primeras lecciones), sino también artísticamente, por medio de las artes útiles y de las bellas artes; los puntos de fenomenologia de la expresión en general, dan los de la expresión artística, la útil y la bella, y son: la expresión; lo expresado; el sujeto; el destinatario; la percepción y comprensión (por el destinatario) y la situación.

Anticipa que el sujeto de la expresión tiene una peculiar dualidad: en la mímica y verbal es sustancia y causa; en el arte -útil o bello- el sujeto se desdobla, la sustancia es el artefacto o la obra de arte, y él es causa de la sustancia; en el caso del arte útil se trata del homo faber, en el de las bellas artes del artista. Sin embargo hay artes en que el mismo ser humano es a la vez sustancia y causa (la danza, la gimnasia...). $Y$ apunta algo de particular interés: que la distinción entre artes sin o con distinción de sujetos, sustancia y causa, podría ser el principio de una clasificación de las artes. En todo caso, la expresión como artefacto o como obra de arte se emancipa del sujeto más que la expresión oral.

$\mathrm{Si}$ bien cuanto dice es importante, evito las finas distinciones y puntualizaciones que hace el doctor Gaos, para intentar aquí sólo una síntesis de su exposición; el interesado encontrará toda la riqueza de sus reflexiones cuando lea los textos originales. La distinción entre artes útiles y bellas artes tiene, sin duda, un antecedente aristotélico.

Las artes útiles tienen una historia cuyas etapas esenciales son: 1) utilización artística del propio cuerpo y de los seres naturales sin transformación alguna de ellos; 2) arte útil fundado en la experiencia y el progreso de ella; 3) o en la ciencia solamente de la mecánica; 4) y en la ciencia moderna toda, fundamentalmente, la Física. En la primera etapa se podría hablar de "útiles", "utensilios" o "instrumentos", en la segunda también se puede usar la palabra "artefacto"; en la tercera, las máquinas; en la cuarta "aparatos" y "técnica".

El artefacto y el sujeto causante de él son dos sustancias, en relación de causalidad - eficiente- final. El productor del artefacto lo ha causado eficientemente como medio para una finalidad.

Lo expresado por el artefacto es su utilidad, para una finalidad. La utilidad parece vinculada al arte; útil o inútil para el hombre es todo lo natural. Las finalidades son innumerables, pero chabrá una finalidad común a todas, genérica, esencial? Es la finalidad entrañada en el principio del "economismo". Los artefactos son medios económicos, vehículos de transpor. te; el modo es el movimiento (aristotélico), ahora bien, los artefactos pueden 
servir para la velocidad o el retardo, los más para acelerar los movimientos humanos; los de retardo están al servicio de los de la aceleración. El hombre ha escogido entre los dos modos la aceleración ¿por qué?.

El sujeto causante de los artefactos, de las artes útiles (tema al que da el autor mayor desarrollo), es el homo faber, el de la inteligencia técnica, de la construcción, el productor, el fabricante. Sus actividades corporales no le bastan para sus satisfacciones biológicas y humanas, necesita de las actividades de más cuerpos que el suyo, pero ¿cómo y por qué no le bastan sus actividades corporales? ¿qué satisfacción necesita o quiere? Ha de ser una satisfacción trascendente. Los artefactos son vehículos de aceleración de su satisfacción, de su felicidad -con el contrapunto de insatisfacción e infelicidad-, por eso el desarrollo vertiginoso de la técnica, de la ciencia, de la física. Y apunta una serie de cuestiones: "¿No es la imagen de nuestra vida actual la de un correr cada vez más aprisa tras la felicidad, cuyo resultado es alcanzar cada vez más aprisa también la infelicidad?" "¿No sería, pues, posible y mejor el retardar el movimiento de las nuevas satisfacciones...? IQue diferente imagen de nuestra vida la que aboceta la idea de una vida regida, no por la aceleración, sino por el retardol"

El destinatario de los artefactos es el mismo homo faber, en cuanto a utilizador, operador, manipulador y manejador de ellos. El fabricante y el destinatario son ambos utilizadores.

La comprensión por los utilizadores no sólo es intelectual sino práctica por excelencia. Deben comprender intelectualmente los artefactos para utilizarlos corporal, manualmente.

La situación de las artes útiles -incluida toda la cultura material, industrial- radica en la convivencia humana material. Esto plantea el tema de nuestro tiempo: la deshumanización o enajenación acarreada o impuesta por el maquinismo y el capitalismo, que debe ser objeto de las ciencias humanas y otras disciplinas filosóficas, no de la Antropología Filosófica en cuanto tal, según dice el doctor Gaos.

Hoy día por "obras de arte" se designan únicamente las de las "bellas artes"; aunque también podrían caber en esa descripción las obras de las artes útiles. Si bien va a considerar el doctor Gaos "Las bellas artes no de la palabra", aclara que la expresión y el sujeto causante de ella, de la obra que es su "expresión artística", tienen afinidad con la expresión mímica y la verbal:

Para los fines de la Antropología Filosófica las obras de arte se dividen en aquellas de la palabra y todas las demás. Aquí prescindirá de expresiones artísticas como, por ejemplo, la danza, para ocuparse sólo en dos expresiones de las bellas artes: una del espacio, que es la pintura, y otra del tiempo, que es la música, ya que no es posible, por razones de límites, que considere el tema del "sistema de las artes". En cuanto a las "artes de la palabra", serán 
tratadas con mayor amplitud en la lección de "La expresión literaria".

Las expresiones artísticas, en cuanto "creaciones", son hechas por la imaginación creadora. El cuadro es un conjunto de manchas de color; la pieza musical consiste en un conjunto de sonidos; la cuestión es la forma, en la que estriba la expresión artística chabrá formas generales de lo artístico...?

El músico imagina un conjunto de sonidos que hace perceptible la ejecución instrumental; pero sólo se traslada el problema: de las formas de los perceptos, que son las obras de arte, a las formas de las imágenes creadoras, que reproducen perceptivamente las obras de arte. Reducir la obra de arte a obra de expresión bella, no hace sino trasladar la cuestión: expresión artística, igual a expresión bella.

¿Qué es lo expresado en o por las obras de arte? En el cuadro el sujeto se objetiva en él, se hace presente como objeto estético; conclusión confirmada por la pintura abstracta y más aún por la música. La pintura abstracta es comparable a la imagen creadora; no reproduce nada, es un objeto nuevo. El cuadro abstracto es el único objeto y el objeto estético; así, también es la música.

La cuestión se plantea ahora así: 1) de las relaciones de los objetos estéticos con la imaginación creadora, el pensamiento, las emociones y mociones de los sujetos, que son los artistas creadores; 2) con los objetos no estéticos.

El cuadro o la pieza musical no notifican directamente lo que hay de pensamiento, que está en las imágenes. El pintor y el músico no son pensadores puros, pero en la creación artística interviene un proceso, un discurso artístico, estético, en el que ocurren ideas de todas clases; es un proceso no sólo de la imaginación creadora, sino del pensamiento creador.

Lo que en un cuadro o pieza musical hay de emocionalidad y mocionalidad está en conjugación con la imaginación y el pensamiento del artista: El pintor empieza por percibir más emocional y hasta mocionalmente que el hombre común, y quizá percibe específicamente de manera pictórica. El músico romántico también (Beethoven, Teoría de la música de Schopenhauer); el post-romántico compone inspirado por la imagen creadora del objeto estético mismo, más patente por lo más puramente creador de la música. La pintura parece poder ser fría, apática, aséptica de sentimentalismo; la música parece reducirse a expresión de emociones y mociones. De un lado las emociones y mociones se expresan mímicamente; de otro, la apercepción emocional y mocional de los perceptos y las imágenes auditivas es mucho más exclusiva que de los visuales; lo visible es mucho más "objetivo".

En fin, por la imaginación creadora, el pensamiento creador, la emocionalidad y mocionalidad artísticas, la obra de arte tiene una relación con la realidad especial e importante: no la de reproducción de tal realidad, sino de la revelación o potenciación de ella. El arte revela en la realidad lo que 
no está en ella perceptible sino para el arte. Así, el arte enriquece, realza, potencia la realidad, antes no estética, y hace obtener de ella satisfacciones peculiares, por lo que el arte es arte de gozar también de la vida en general. La cultura estética y la educación para ella, pertenecen a las Humanidades, a las disciplinas "formadoras del hombre más perfecto posible".

La realidad preestética debe referirse a lo bello natural; quizá no haya más belleza que la proyectada por el hombre o impuesta por sus potencias estéticas y artísticas.

Hemos determinado, dice el doctor Gaos, qué es lo expresado en o por las obras de arte. Pero ¿por qué no tomamos la cosa de otro lado... por qué no partimos de las expresiones mismas "bello" y "feo"? "Bello" y "feo" tienen la notificación y designación inequívocamente estética, que es la única, a que se referirá. Para el hombre lo bello es humano, además de lo bello natural. Si la belleza, hoy considerada con autonomía respecto a lo moral, y la fealdad se distribuyen entre los existentes, como parece más ajustado a los fenómenos, desaparece la trascendentalidad de los sumos conceptos estéticos. "Bello" y "feo" parecen universales, así, pueden haber conceptos estéticos individuales. "Bello" y "feo" son conceptos de modos, de los modos estéticos "bello" y "feo"; lo modalizado son las obras de arte y lo natural. Un artefacto útil puede ser bello o feo, aunque no sea obra de intención estética. Hay belleza y fealdad en los cuerpos humanos, y hasta en lo psiquico, independiente de lo moral.

¿Qué modos de las obras de arte, y de lo natural, son "bello" y "feo"? Parecen cualidades; actividades no parecen serlo, aunque sin duda puede serlo lo modalizado por la belleza y la fealdad; relaciones, parecen poder serlo: "bello para", "feo para". Pero ¿qué relaciones serán belleza y fealdad? Parecen ser causas de satisfacciones o insatisfacciones sui generis; mas, si tal es el caso, entonces resultarían una especie de satisfacciones e insatisfacciones morales. No obstante la antes mentada autonomía de lo estético respecto de lo moral, no hay nada "humano" que se sustraiga al ámbito de la moralidad, ni el arte ni lo estético, o lo bello y feo en general. Si lo bello y lo feo son especies de satisfacciones e insatisfacciones "humanas", y éstas en general son buenas o malas, son morales. Se añaden dos especificaciones: 1) se trata de conceptos "indicativos", "ostensivos", como "color" "amor"; 2) las formas causantes de la satisfacción o insatisfacción estética, serían asunto de una Teoría del Arte fundada en la Historia del Arte, y de una Teoria de las formas naturales bellas y feas, fundada en una Historia de la belleza natural para los hombres, de que apenas hay la idea.

En conclusión: "bello" y "feo" son conceptos que tendrian por objeto la satisfacción o insatisfacción sui generis causadas por las obras de arte y los objetos naturales. Ahora bien, si "bello" y "feo" son especies de "bueno" y "malo", entonces se plantean cuestiones éticas. "Bello" y "feo" no son 
modos cuantitativos, pero son susceptibles de modalización cuantitativa: intensidad, jerarquía, de bellezas y fealdades, es decir de satisfacciones e insatisfacciones estéticas.

El sujeto causante de la expresión artística bella es el artista; de la expresión bella de la naturaleza, el hombre a quien ésta le parece bella.

El destinatario de la expresión bella de la naturaleza es el propio sujeto; el de la obra de arte va desde el destinatario individual de la obra, hasta el público de los artistas y de la "contemplación estética".

La comprensión consiste en "percibir" las formas causantes de la satisfacción o insatisfacción estética, de suerte que se "experimenten" éstas, lo que tiene por condición absorberse en la percepción de las formas, y no en la conciencia de las emociones y mociones no estéticas, en lo erótico, por ejemplo. La percepción de la forma y comprensión toda de la obra de arte como tal es máxima en la crítica de arte y en la contemplación educada o ilustrada por ella.

La situación constituida por las obras de arte es el mundo social, humano, del arte; y la que constituye la belleza natural para los hombres, es una porción de la historia más arriba sugerida.

"La expresión literaria" es el tercer y último tema con que completa el doctor Gaos su indagación estética, en relación con la Antropología Filosófica, o más bien; como parte de ella. Inicia el asunto con algunas consideraciones previas: que las artes de la palabra no se reducen a la literatura, sino que son todas aquellas en que ésta tiene lugar y ejerce una función especial, principal, como son el teatro, el cine, la televisión; que hay que tomar la bella literatura en toda la extensión clásica: épica, lírica, dramática, oratoria, histórica, didáctica; que en todo ello radica lo bello en la expresión verbal artística, que es la expresión literaria en sentido estricto; que la expresión literaria es diferente a toda otra expresión artística bella, por ser expresión verbal conformada bellamente por el arte literario. $\mathrm{Y}$ pasa al análisis fenomenológico de acuerdo con los puntos establecidos.

La expresión consiste en las obras literarias mismas, no sólo las escritas o reproducidas por escrito, sino también las orales, poéticas $\mathbf{u}$ oratorias. Tiene los dos ingredientes: de la notificación de pensamientos y designación de objetos, y la significación de emociones y mociones. Los casos de la literatura actual en que se tiende ya a no notificar pensamientos ni designar objetos, ya a no significar emociones y mociones sino a promover meras imágenes creadoras, o meras sensaciones, no pueden considerarse sino como casos límites, constituidos por una sola parte de los ingredientes de la expresión literaria cabal. No hay pensamiento ni objeto que no pueda entrar en una obra literaria; hasta los discursos científicos, matemáticos, lógicos, pueden insertarse en algo que sea bella literatura. En cuanto a las emocio- 
nes y mociones, son capitales una distinción y una adición. La distinción: entre las emociones y mociones significadas, que son las del literato relativas a los objetos designados, y las objetivadas como parte de los objetos designados o la totalidad de éstos. La adición: las emociones y mociones no se reducen a las del literato relativas a los objetos, sino que abarcan a sus expresiones mismas; asi el literato escribe con una voluntad de estilo y con una conciencia directa de su espontaneidad artística.

¿En dónde está la forma, bella en sentido derivado, causante de la satisfacción estético-literaria, bella en sentido primario? Está en todo ello y en las imágenes que entran como objetos designados; en las imágenes de los perceptos designados; en las causadas por los pensamientos notificados; o por las emociones o mociones significadas. En la expresión literaria entran las imágenes en las formas mismas.

La obra literaria es obra de la imaginación creadora, ante todo de los objetos designados, ficticios, imaginados creadoramente, así, la expresión literaria actualiza y potencia los objetos "reales", hace ver la vida o la naturaleza como no se hubiese visto sin ella, causando la peculiar satisfacción estética. La literatura plantea el problema de la imaginación de emociones y mociones; por eso la "explicación de textos" que hace percibir, por ejemplo, las características estilísticas y comprender las intenciones de que son efecto, contribuye a una satisfacción estética superior y educa para recibirla.

El pensamiento interviene más en la literatura que en las artes no de la palabra, por ser la expresión propia de él la verbal. Una complicación es la expresión verbal vulgar, no del autor sino de los personajes ceados por él, que pueden ser no literarias o bien sí, cuando presentadas por el autor como literarias de un personaje.

La forma literaria, o bella, está, en resumen, en lo que las obras del arte literario tienen en común con las de las artes no literarias; pero la obra literaria es causa de la satisfacción estética específicamente literaria. Al doctor Gaos le parece más que dudoso que haya satisfacciones estéticas específicamente diferentes, causadas por las obras de pintura, música, literatura, y no simplemente una misma y única especie de satisfacción estética.

El sujeto de la expresión literaria es el artista, el literato; error sería tomar por esencia del artista literario la del escritor. El artista literario es una especie del hombre estético creador, una especie. del hombre estético en general, de la que la otra especie es el "contemplador".

El destinatario tiene también una historia, desde el público oyente del primitivo poeta, hasta el gran público internacional de los escritores de la Weltliteratur actual, pasando por los destinatarios individuales de obras, principalmente de poesía, como la mujer para la que el poeta escribe una poesía.

La percepción y comprensión de la obra literaria por el destinatario 
consistiría en que éste debe pensar los mismos pensamientos, objetivar los mismos objetivos, percibir las emociones y mociones de la psique del autor relativas a los objetos; pero estas relaciones no pueden ser de identidad, sino que las "creaciones" literarias son recreadas e interpretadas por cada lector de cada generación de ellos, con matices individuales, con notorias divergencias históricas.

La situación de la obra literaria está condicionada por su historicidad, que se pone de manifiesto en la crítica literaria y ciencia histórica y teórica de la literatura, conjunto que no es sino la Historia literaria misma.

El doctor Gaos llega a la parte final de su indagación estética y ahora dice que se impone dar razón de la significación antropológico-filosófica del arte bello en general, y del literario en especial, caracterizando al "hombre estético", como antes al homo faber y al de la razón pura y práctica.

Desde el momento en que el hombre habla y conversa se revela como "animal racional"; desde el momento en que fabrica y usa útiles, como homo faber; desde el momento en que hace arte y lo goza, como "hombre estético".

La razón humana está supremamente en los conceptos trascendentales y morales, cuya raíz está en la constitución moral del hombre, en su ser sujeto a satisfacciones e insatisfacciones, amor y odio y voluntad.

Lo faber del hombre radica en la inteligencia técnica, y ésta a su vez en la utilización de la aceleración de la actividad para la finalidad moral del estado de satisfacción, como concibe el hombre moral o de la razón práctica, la felicidad.

Lo estético del hombre está esencialmente en la satisfacción estética. Lo indispensable ahora es la localización de la satisfacción estética y del hombre estético en relación con la razón pura y práctica y la inteligencia técnica, o sea dentro del hombre total.

La satisfacción estética la refirió Kant al juicio, como facultad que agregar a las razones pura y práctica, para completar el sistema de la subjetividad trascendental. Pero la satisfacción estética no párece ser cosa de "juicio". Parece más justa la idea tradicional de ver la satisfacción estética como arquetipo de lo irracional. En la historia hay filosofías que ponen la satisfacción estética o lo bello en el pináculo de la jerarquía de los bienes o de los valores. Esta concepción no parece infundada, si se atiende a los fenómenos. Quiérese significar que si el estado de felicidad fuese asequible, lo coronaría una satisfacción estética infinita... y así la moralidad, el bien, culminaría, teleológica y arquitectónicamente, en el goce estético, punto final de las relaciones entre lo moral y lo estético.

A tal concepción parece, sin embargo, oponerse otra; la del progreso histórico de la Humanidad basado en la racionalidad del hombre, e incluso en la razón pura. ¿No tiende, la dominación creciente de la ciencia y la téc- 
nica sobre todo lo humano, a acabar relegando el arte, con lo irracional en general, a un pasado que acabará, a su vez, siendo arcaico, ancestral...?

¿O a compás con la tecnificación, cientificación, racionalización creciente de lo humano, del hombre, no se impondrán reacciones de éste como la de nuevas formas de arte, potentes precisamente para vivir y operar enmedio de la creciente tecnificación...?

¿Qué será el hombre esenciälmente? ¿Razón pura? ¿moralidad motivante de la razón pura y culminante en la satisfacción estética? y ¿cómo lo será? ¿Acaso antinómicamente...?

He procurado hasta aquí una exposición sintética, a mi modo, de la indagación estética del doctor Gaos, que espero ayude a una más rápida comprensión de sus reflexiones, pero, naturalmente, debe tomarse con reservas, pues no sé hasta qué punto las haya seguido con suficiente fidelidad; en todo caso me pareció necesario hacerlo para poder apoyar algunos comentarios que expondré a continuación.

Sorprende que en general, y hasta cierto punto, se haya atenido a concepciones clásicas del hombre, como la de "animal racional" y la de su esencialidad, radicada en esto o en aquello, ya que justamente la Antropología Filosófica se construye con las indagaciones fenomenológicas cuyas conclusiones dan las caracteristicas de alguna esencia del hombre, siempre problemática. Por otra parte, fuera de los análisis, la actitud del doctor Gaos consiste más en planteamiento de posibilidades que en afirmaciones categóricas, por eso el empleo de frases como: "parece que..." "quizá...", o bien las cuestiones presentadas interrogativamente. Esto no obsta para que vuelque toda su experiencia con riqueza de ideas y de procesos de ellas con seguridad absoluta.

Las consideraciones estéticas del doctor Gaos abarcan todo lo existente, ya que no sólo plantea la división entre "Artes útiles" y "Bellas Artes", de la palabra o no, sino que incluye lo bello natural, para el hombre; se trata, pues, de una estética totalizadora.

En cuanto a las "Artes útiles", el análisis nos lleva por sus pasos: artefacto como medio para una finalidad; economismo para acelerar o retardar; el hombre ha escogido la aceleración para alcanzar su satisfacción, para la felicidad. Toda la cultura material, industrial -que trae aparejada la deshumanización y la enajenación-, radica en la convivencia humana material. Razón tiene el doctor Gaos cuando pregunta si con toda la aceleración de la vida actual más bien lo que se alcanza es la infelicidad, y, nostálgicamente, trae a colación la posibilidad de la vida basada en el retardo, que sin duda serfa más humana, pero quizá ya imposible a la altura de estos tiempos.

En "Las bellas artes no de la palabra" el desarrollo del tema es exce- 
lente, aunque en parte resulta menos novedoso. Todo lo relativo a lo bello y lo feo acaba por asociarse a lo bueno y lo malo y, por lo tanto, viene a ser una especie de satisfacción e insatisfacción moral, no obstante que con anterioridad había admitido que la Belleza puede ser considerada con autonomia, respecto a lo moral. Pero su conclusión categórica es que nada humano puede sustraerse a la moralidad. Si bien dice que quizá la belleza natural no es sino la proyectada por el hombre, ello es evidente y aceptado que así es; pero sugiere con novedad, que debería hacerse la Historia de la belleza natural, para el hombre, precioso tema que podría indagarse a través del arte y de la literatura. En suma lo bello y lo feo son conceptos que tienen por objeto la satisfacción o insatisfacción estética, causadas por las obras de arte y por los objetos naturales.

En verdad muchos de los aspectos analíticos, referentes a las bellas artes no de la palabra podrían aplicarse a "la expresión literaria", y viceversa, ya que se trata, al fin y al cabo, de artes bellas. El mismo doctor Gaos pone en duda que haya satisfacciones estéticas diferentes, aunque las obras que las provocan sean de pintura, de música o de literatura, y concluye que no hay sino una única especie de satisfacción estética, como en rigor parece ser.

En los casos de la literatura actual, en que sólo se promueven meras imágenes o meras sensaciones, pueden considerarse casos límites, "constituidos por una sola parte de los ingredientes de la expresión literaria cabal". Algo análogo sucede, digo yo, en relación con el arte abstracto en sus diferentes expresiones, parece como si volitivamente el artista hubiera suprimido una serie de posibilidades para atenerse a un reducido número, y aun a una sola de ellas.

La obra literaria, como toda obra de arte, es obra de la imaginación creadora, con la intervención del pensamiento y de las emociones y mociones del artista. La explicación de textos, dice con razón sobrada, contribuye a una satisfacción estética superior y educa para recibirla. En verdad la función primera de la crítica de arte, agrega, es la comprensión total de la obra de arte, pero hay también la contemplación educada o ilustrada por ella. Cada individuo y cada generación recrea e interpreta de manera distinta la obra literaria, o la obra de arte, o el mundo de los objetos naturales, todo lo cual remite a su historicidad, a la historia literaria, del arte, y de la crítica. Todo eso está muy bien y no merece sino aprobación.

A manera de conclusiones de su indagación estética, el doctor Gaos plantea las cuestiones finales. Definido el "animal racional" desde el momento que habla y conversa; el homo faber, con su inteligencia técnica utilizada para alcanzar aceleradamente la finalidad moral: la felicidad; y el "hombre estético" (que en un pasaje llama también "animal estético") como creador de arte, que así satisface su necesidad moral de belleza y con sus obras promueve semejante satisfacción en otros, la conclusión de que todo radica en 
la constitución moral del hombre le da sentido clásico, tradicional, hasta escolástico. Sin embargo, hay que entender que se trata de una moralidad y de una estética inmanentes, basadas en los fenómenos de las actividades humanas, a su vez destinadas a alcanzar satisfacciones, a lograr idealmente la felicidad en este mundo, aunque en esa carrera se encuentren los tropiezos: la insatisfacción, la infelicidad. Ese afán de felicidad vital, existencial, mundana -material y espiritual-, sin trascendencia metafísica o metahumana, con antecedentes a lo menos desde la Ilustración, identifica la descripción de los fenómenos humanos y las conclusiones a que llega el doctor Gaos con la corriente de ideas y actitudes de nuestro mundo y tiempo, que ha suprimido toda creencia religiosa, porque se ha desligado del sentimiento supraterrenal y suprahumano, con notable mengua de sus posibilidades.

En verdad, si no fuera porque se ha relacionado el goce estético con el bien, con lo que todo entra en el campo de la moralidad, podría pensarse que se trata de una estética hedonista, pero no se puede llegar aquí a tal conclusión.

Cabe preguntarse si en el mundo de la inmanencia tiene justificación la moralidad y la estética - utilitaria o espiritual- y, desde luego, se piensa en la dignidad humana per se (Kant), sin duda la única justificación satisfactoria moralmente en ese mundo intrascendente y autosuficiente.

Las cuestiones finales que plantea el doctor Gaos, como cuestiones, es decir, como posibilidades o como problemas sin solución a la vista, se derivan de las conclusiones anteriores.

En primer lugar aparece la contrapartida del "animal racional" cuando se refiere a la satisfacción estética, que Kant radica en el juicio y que el doctor Gaos considera, con sentido tradicional, más bien como el "arquetipo de lo irracional". Así surge la concepción dual del hombre como "animal racional è irracional", sin duda más ajustada a los fenómenos de la existencia humana. Por otra parte, si la estética se coloca en la cumbre de la felicidad, como quieren algunas filosofías, entonces el bien, la moralidad, dice el doctor Gaos, culminaría en el goce estético, punto final entre lo moral y lo estético; sería como la resolución sintética de la antinomia.

Mas existe la concepción opuesta, tan vigorosa en nuestros días, del progreso humano basado en la racionalidad y aun en la razón pura, en la que se desenvuelve triunfante el homo faber, y el doctor Gaos plantea una cuestión, que es la prueba de ese triunfo, cuando dice: zno tiende la dominación de la ciencia y la técnica a acabar relegando el arte, y todo lo humano irracional, a un pasado, arcaico, ancestral? En efecto, ya no es tan sólo un síntoma sino un hecho que existe una corriente de opinión, inclusive entre artistas y estetas, que considera al arte y la estética como pertenecientes al pasado, como ya inoperantes por carecer de sentido; por eso también se ha producido el "antiarte". 
Y vuelve a preguntar el doctor Gaos: ¿No se impondrán reacciones, nuevas formas de arte, potentes para vivir y operar en medio de la creciente tecnificación? A lo que puede contestarse: que ya existen artes que a base de medios técnicos industriales, mecánicos, logran obras de interés espectacular, como el cinetismo y otras estructuras, dinámicas o no; así los artistas intentan colocarse a la altura del mundo cientifico y técnico actual, logrando obras a veces sensacionales, recreos para la mirada, absolutamente inmersa en un esteticismo ya designado como "del sigio xxI"; y se ha dado el caso de que un científico abandone su quehacer propio para dedicarse al nuevo arte que, sin duda, requiere para su mayor eficiencia conocimientos amplios, científicos y técnicos.

Las cuestiones se multiplican al final de las reflexiones estéticas del doctor Gaos: ¿qué será el hombre esencialmente? ¿moralidad motivante de la razón pura y culminante en la satisfacción estética? ¿cómo será? ¿acaso antinómicamente? Tal parece que deberíamos quedarnos perplejos ante tales cuestiones, mas se antoja darles otra vuelta. Se han dado en la historia muchas definiciones del hombre, unas más justas que otras, pero todas insuficientes en su radicalidad para alcanzar la "esencia". En los textos mismos considerados, el doctor Gaos empieza por atenerse a la clásica definición de "animal racional" y acaba por tener que admitir al "animal irracional" que es el hombre estético, y sin duda ambas definiciones son verdaderas. Que el hombre sea moralidad motivante de la razón pura y culminante en la satisfacción estética, es verdad si se juzga por las reflexiones mismas del doctor Gaos. Que acaso viva antinómicamente, parece la verdad más satisfactoria. Porque, racionalmente se pueden puntualizar las antinomias, pero en la vida misma se viven sin más, y a veces se sintetizan en el sueño, en la imaginación y en el arte. Y, así, enmedio de una variedad de definiciones puede uno concluir: que si alguna esencia tiene el hombre es su complejidad.

Las reflexiones sobre los aspectos estéticos del hombre según han sido expuestas por el doctor Gaos nos hacen conscientes de los procesos del arte utilitario y de la creación estética, asł como de los problemas que entrañan al "señalar y acotar el lugar y la raíz de las cuestiones en la esencia del hom. bre". En verdad, su valor consiste en ser una estética totalizadora de lo existente, incluyendo las cuestiones capitales de la creación artística y estética de nuestro tiempo, vinculadas menos a lo que el hombre hace y es, y más a lo que va haciendo y siendo.

Queda pendiente, claro está, la cuestión de cómo se inserta esa estética en la Antropología Filosófica y en la filosofía del maestro.

INSTITUTO DE INVESTIGACIONES ESTÉTICAS

Justino FERnÁndez

Universidad Nacional Autónoma de México 